\title{
Are overweight women at increased risk of obesity following pregnancy?
}

\author{
H. E. Harris ${ }^{1,2 *}$, G. T. H. Ellison ${ }^{2,3}$, L. M. Richter ${ }^{4}$, T. De Wet ${ }^{5}$ and J. Levin ${ }^{4}$ \\ ${ }^{1}$ Communicable Disease Surveillance Centre, Public Health Laboratory Service, London NW9 5EQ, UK \\ ${ }^{2}$ Maternal and Child Health Research Programme, School of Chemical and Life Sciences, University of Greenwich, \\ London SE18 6PF, UK \\ ${ }^{3}$ Institute of Urban Primary Health Care, Alexandra Health Centre, Johannesburg, South Africa \\ ${ }^{4}$ Centre for Epidemiological Research in Southern Africa, Medical Research Council, Pretoria, South Africa \\ ${ }^{5}$ Birth to Ten, Urbanisation and Health Programme, Medical Research Council, University of the Witwatersrand Medical \\ School, Johannesburg, South Africa
}

(Received 20 March 1997-Revised 9 December 1997-Accepted 16 December 1997)

\begin{abstract}
Longitudinal studies suggest that women who already have a high BMI are at greater risk of maternal obesity than their lighter counterparts. The aim of the present study was to investigate this possibility by examining the relationship between reproductive history and maternal BMI in a community of 627 women from South Africa with a high prevalence of obesity. Standardized questionnaires were used to obtain detailed sociodemographic and behavioural information, while maternal weight and height were both measured at the time of the interview. Analysis of covariance (ANCOVA) showed that maternal age $\left(r^{2} 0 \cdot 015, P=0.001\right)$, smoking status $\left(r^{2}\right.$ $0.012, P=0.036)$, and social support $\left(r^{2} 0.011, P=0.006\right)$ were all independently associated with maternal BMI. If overweight women were at increased risk of maternal obesity, then the positive relationship between reproductive history and maternal BMI should be enhanced in this relatively obese community, yet the ANCOVA models showed no independent association between gravidity and maternal BMI after controlling for the effects of confounding factors. Although previous longitudinal studies have found a positive association between prepregnant weight and long-term weight gain, this relationship might arise because overweight women gain more weight over a fixed period of time than normal weight women, and therefore they may appear to be at greater risk of pregnancy-related weight gains. Overweight women are at greater risk of weight gain generally, but there is little unequivocal evidence to suggest that they are at any increased risk of maternal obesity, when compared with women of lower BMI.
\end{abstract}

\section{Maternal obesity: Weight gain: Pregnancy}

Sheldon (1949) first coined the term 'maternal obesity' to describe the "common observation that women may... develop a severe obesity after having a baby'. Since this time, several risk factors for maternal obesity have been identified, the most important of which are thought to be: high gestational weight gain (Greene et al. 1988; Keppel \& Taffel, 1993; Parker \& Abrams, 1993; Boardley et al. 1995; Scholl et al. 1995; Harris et al. 1997b), high prepregnant body weight (Schauberger et al. 1992; Stevens-Simon \& McAnarney, 1992; Boardley et al. 1995), low socioeconomic status (Parker \& Abrams, 1993), and cessation of smoking (Öhlin \& Rössner, 1990).

In particular, it has been suggested that women who already have a high BMI are at greater risk of maternal obesity (Sheldon, 1949) when compared with their lighter counterparts (Schauberger et al. 1992; Stevens-Simon \& McAnarney, 1992; Boardley et al. 1995). By comparing postpartum body weight with body weight recorded before pregnancy, these longitudinal studies are able to identify maternal characteristics, such as prepregnant BMI, that are associated with greater weight gains. However, two possible conclusions can be drawn from the positive association that is commonly observed between prepregnant BMI and long-term weight gain following pregnancy. It could be that overweight women (BMI $>26 \mathrm{~kg} / \mathrm{m}^{2}$; Institute of Medicine, 1990) are at increased risk of gaining weight in association with pregnancy. However, these women may simply 'appear' to be at greater risk of 
pregnancy-related weight gains because they gain more weight over a fixed period of time than do women of low or normal $\mathrm{BMI}\left(\mathrm{BMI} \leq 26 \mathrm{~kg} / \mathrm{m}^{2}\right.$; Institute of Medicine, 1990), regardless of pregnancy. If this were the case, overweight women would not be at any increased risk of maternal obesity, simply at greater risk of obesity generally. The aim of the present study was to investigate each of these possibilities by examining the relationship between reproductive history and maternal BMI in a community of women from South Africa with a high prevalence of obesity (Harris et al. 1996). If overweight women are at increased risk of maternal obesity, then the positive relationship between reproductive history and maternal BMI (Cederlöf \& Kaij, 1970; Heliövaara \& Aromaa, 1981; Baecke et al. 1983; Brown et al. 1992; Williamson et al. 1994) should be enhanced in this community. Conversely, a reduced relationship between reproductive history and maternal BMI would suggest that overweight women are not at increased risk of maternal obesity.

\section{Materials and methods}

\section{Sample}

The association between maternal BMI and reproductive history was investigated using mothers enrolled in South Africa's 'Birth to Ten' longitudinal birth cohort study (Richter et al. 1995). From this cohort, all mothers whose residential addresses at the start of the study were given as Greater Soweto, and who were subsequently weighed at the time of the 5-year follow-up interview, were included in the present study. Of the 753 mothers eligible for inclusion in the study, nineteen were excluded because they were pregnant at the time of the follow-up interview, which might have resulted in a higher than normal body weight. Likewise, to minimize the potential effect of recent pregnancies, a further seventy-two mothers who had delivered a child less than 12 months before their followup interview, were excluded from the study. A further thirty-five cases with missing data for one or more of the variables listed in Table 1 were also excluded. The final sample comprised 627 non-pregnant mothers, none of whom had delivered a child within 1 year of the 5-year follow-up interview. On average, these 627 women were of lower gravidity ( $t 3.28, P=0.001$ ) yet they did not differ from the 126 excluded women in any of the other characteristics listed in Table 1. For this reason there was little evidence that women included in the study were unrepresentative of the sample as a whole (see Table 1).

\section{Study design}

A cross-sectional study design was chosen to enable the researchers to tease out the relative contribution of 'an obese lifestyle' from any differential effect of pregnancy on weight gain by obese individuals. A longitudinal design was rejected because it would have been unable to separate these two issues since both an 'obese lifestyle' and any differential effect of pregnancy in obese individuals occur simultaneously. If pregnancy has a differential effect on the long-term weight gain of obese individuals then a cross- sectional analysis of an obese population, which controls for differences in age, would show this by demonstrating a steeper slope of parity on body weight than that observed in leaner populations.

A control group of nulligravid women was not used in this cross-sectional study, since this approach assumes that the pattern of weight gain over time is the same among women who have one or more children ('mothers') as among those who have no children (either by chance, or because they have chosen not to have children). There is substantial evidence that this assumption is false, because it is impossible to obtain nulliparous or nulligravid controls who are matched to parous gravid cases in this regard, and there is good evidence that permanently nulliparous or nulligravid women in well-nourished communities tend to gain more weight over time than parous women who do not experience further pregnancy (Williamson et al. 1994). Therefore, nulligravid control women were not included in the present study.

To assess the independent association between gravidity and maternal BMI, analysis of covariance (ANCOVA) was used to control for a variety of potential confounders between mothers of differing gravidity (see Table 1). The form of the regression was assessed by examining a scattergram of the residuals, which on examination revealed no pattern between predicted values and standardized residuals. Duration of breast feeding was not included in the analyses since duration of breast feeding was remarkably uniform within the 'Birth to Ten' mothers from Greater Soweto, with mothers displaying traditional infant feeding practices which are characterized by prolonged breast feeding (Ellison et al. 1997a,b). As such, all mothers in the present sample could be considered prolonged breast feeders (Ellison et al. 1997a,b).

Standardized questionnaires were used to obtain detailed sociodemographic and behavioural information during the 5-year follow-up interviews of the 'Birth to Ten' study, which were conducted in 1995 and 1996. Housing tenure and employment status were included in the model as dichotomous variables, while maternal age was included as a continuous variable. Stress, social support and socioeconomic status were all composite indicators derived from maternal responses to a suite of questions describing their experience of stressful situations, social relationships, household commodities, and private medical insurance (see Appendix). Smoking behaviour was classified into four categories: daily smokers, occasional smokers, ex-smokers and non-smokers, while gravidity was included in the model as a factor (one to nine pregnancies). Maternal weight and height were both measured in light clothing without shoes, using the same measuring tape and set of scales (scale: Soehnle 7306.00, Post Foch 1265, D-71535, Marrhardt, Germany; tape: Microtoise 04 116, France).

\section{Results}

The sample characteristics are summarized in Table 1. On average, mothers were very overweight, with a mean BMI of $27.8(\mathrm{SE} 0.2) \mathrm{kg} / \mathrm{m}^{2}$. They had an average of 2.5 pregnancies, and were on average 30 years old (see Table 1 ). The vast majority did not smoke (93.6\%), less than a 
Table 1. Sociodemographic, anthropometric, and behavioural characteristics of the 627 mothers included in the analyses and the 126 mothers who were excluded from the analysest

\begin{tabular}{|c|c|c|c|c|}
\hline \multirow[b]{2}{*}{ Maternal characteristic } & \multicolumn{2}{|c|}{ Mothers included ( $n$ 627) } & \multicolumn{2}{|c|}{ Mothers excluded ( $n$ 126) } \\
\hline & Mean & SE & Mean & SE \\
\hline \multicolumn{5}{|l|}{ Sociodemographic } \\
\hline Maternal age (years) & $30 \cdot 38$ & 0.26 & $29 \cdot 42$ & 0.52 \\
\hline Gravidity (1-9) & 2.51 & 0.06 & $2.99^{* * \star}$ & 0.13 \\
\hline Socioeconomic status $(0-4)$ & 1.62 & 0.03 & 1.63 & 0.09 \\
\hline $\begin{array}{l}\text { Housing tenure (\% owner occu- } \\
\text { pied) }\end{array}$ & 47.8 & & 50.0 & \\
\hline Employment status (\% employed) & 31.3 & & $26 \cdot 2$ & \\
\hline \multicolumn{5}{|l|}{ Anthropometric } \\
\hline Maternal height (m) & 1.58 & 0.002 & 1.59 & 0.004 \\
\hline Weight $(\mathrm{kg})$ & 69.46 & 0.59 & $70 \cdot 60$ & 1.46 \\
\hline $\mathrm{BMI}\left(\mathrm{kg} / \mathrm{m}^{2}\right)$ & 27.78 & 0.22 & 28.03 & 0.55 \\
\hline \multicolumn{5}{|l|}{ Behavioural } \\
\hline \multicolumn{5}{|l|}{ Smoking status: } \\
\hline Non-smoker (\%) & 93.6 & & 95.8 & \\
\hline Ex-smoker $(\%)$ & 2.6 & & 1.7 & \\
\hline Occasional smoker (\%) & 1.6 & & 0.8 & \\
\hline Daily smoker (\%) & $2 \cdot 2$ & & 1.7 & \\
\hline Stress $(0-20)$ & 3.87 & 0.10 & 3.67 & 0.23 \\
\hline Social support (5-17) & 11.50 & 0.21 & 11.50 & 0.09 \\
\hline
\end{tabular}

Mean value was significantly different from that for mothers included, $* * * P<0.001$.

$\uparrow$ Differences were assessed by the $t$ test (continuous data) or the $\chi^{2}$ test (categorical data).

third $(31.3 \%)$ were employed outside the home, and about one half owned their dwellings $(47.8 \%)$. These dwellings were of various construction, and ranged from houses and cottages to flats, shacks, garages, rooms, and hostels. Nevertheless, most of these dwellings had electricity (97.9\%), and compared with similar urban communities in other developing countries, these women were relatively wealthy: nearly a third $(30.3 \%)$ had access to a motor vehicle, $18.3 \%$ had private medical insurance and $15.6 \%$ had a washing machine.

Univariate analyses showed BMI to be positively associated with both maternal age $(r 0.282, P<0.001)$, and gravidity $(r \quad 0.255, P<0.001)$. There were no significant associations between BMI and housing tenure, employment status, or stress $(P>0 \cdot 1)$. Although there was a weak tendency for BMI to be positively associated with socioeconomic status $(r 0.078)$ and social support $(r 0.074)$, these correlations were not statistically significant $(P>0.05)$. Likewise, mothers who smoked daily had lower BMI than those who smoked less frequently, or not at all $(F$ $2.43, P=0.073$ ). While there was no association between socioeconomic status and social support $(r \quad 0.058$, $P=0.146$ ), socioeconomic status was negatively correlated with stress $(r-0 \cdot 144, P<0.001)$, such that mothers of lower socioeconomic status had significantly higher levels of stress. Similarly, social support was negatively correlated with stress $(r-0.121, P=0.002)$ such that mothers with high levels of social support had lower levels of stress.

To assess the independent association between gravidity and maternal BMI, ANCOVA was used to control for potential confounders between mothers of differing gravidity. After controlling for the effects of confounding, three maternal characteristics were independently associated with BMI, and together these accounted for $10.3 \%$ of the variance in BMI after adjusting for available degrees of freedom (see Table 2). To improve the predictive power of the ANCOVA model, those variables that explained the least amount of variance were removed one by one, in a backward, stepwise approach, until the model that explained the highest adjusted variance was obtained. Housing tenure $\left(r^{2}<0.001\right)$ and employment status $\left(r^{2}<0.001\right)$ were both removed from the original model. The final model contained six variables which explained $10.6 \%$ of the variance in BMI, after adjusting for the available degrees of freedom (Table 3 ). Of these variables, maternal age $\left(r^{2} 0.015, P=0.001\right)$, smoking status $\left(r^{2} 0.012\right.$, $P=0.036)$, and social support $\left(r^{2} 0.011, P=0.006\right)$ were all independently associated with maternal BMI (see Table 3). Younger mothers, those who smoked regularly and those with little social support had lower BMI. There was no significant independent effect of gravidity on maternal BMI after controlling for confounding factors (see Table 3 and Fig. 1), although it is possible that the impact of gravidity on maternal BMI had been obscured by bias associated with the relatively few women of high gravidity (see Fig. 1). To eliminate this possibility, gravidity was recoded by grouping together mothers of parity six or more $(1,2,3,4,5$ and $6+)$ and repeating the analysis. In this model (adjusted $r^{2} 0.104$, d.f. 14 and 626, F 6.19, $P \ll$ $0.001)$ there remained no significant association between maternal BMI and gravidity $\left(r^{2} 0.014, F 1.99, P=0.079\right)$.

\section{Discussion}

If overweight women were at increased risk of maternal obesity, we would expect there to have been a strong positive relationship between gravidity and maternal BMI in this obese population. However, this was not the case. Although gravidity was positively correlated with maternal BMI, the ANCOVA models showed that there was no independent association between gravidity and maternal BMI, after controlling for the effects of confounding factors. As such, it appears unlikely that overweight women 


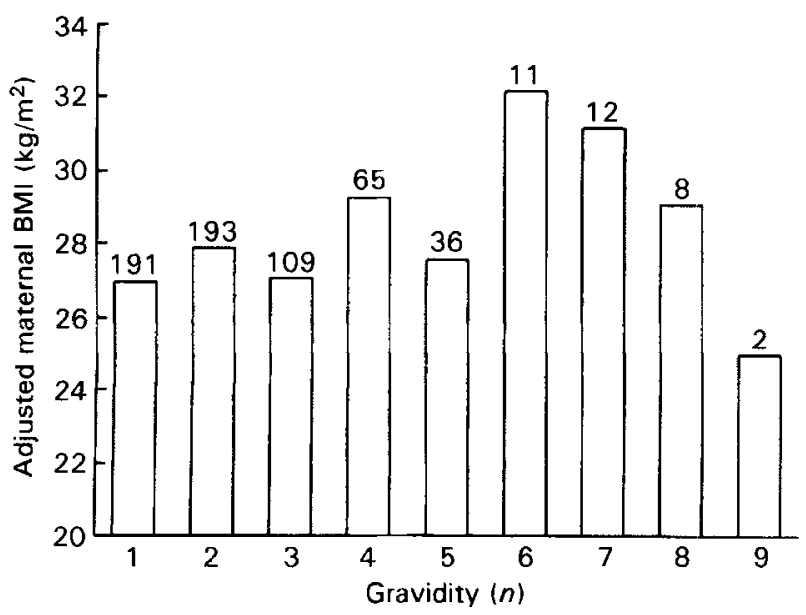

Fig. 1. Mean adjusted maternal BMI $\left(\mathrm{kg} / \mathrm{m}^{2}\right)$ for women of different gravidity. Sample sizes are shown at the head of each bar.

are at greater risk of maternal obesity. Although previous longitudinal studies have found a positive association between prepregnant weight and long-term weight gain (Schauberger et al. 1992; Stevens-Simon \& McAnarney, 1992; Boardley et al. 1995), it seems possible that this relationship might arise because overweight women gain more weight over a fixed period of time than women of normal weight. Therefore, overweight women might simply 'appear' to be at greater risk of pregnancy-related weight gains. However, the present study included only those women who had one or more pregnancy and was therefore unable to assess whether there was any differential impact of a first pregnancy on long-term weight gain.

Table 2. The full analysis of covariance model with maternal BMI as the dependent variable*

\begin{tabular}{|c|c|c|c|c|}
\hline $\begin{array}{l}\text { Factors } \\
\text { Gravidity: }\end{array}$ & \multicolumn{2}{|c|}{$\begin{array}{l}\text { Adjusted maternal } \\
\text { BM! }\left(\mathrm{kg} / \mathrm{m}^{2}\right)\end{array}$} & $\frac{F}{1.52}$ & $\frac{P}{0.148}$ \\
\hline $\begin{array}{c}\text { Gravidity: } \\
1 \\
2 \\
3 \\
4 \\
5 \\
6 \\
7 \\
8 \\
9\end{array}$ & & & 1.52 & 0.148 \\
\hline $\begin{array}{l}\text { Housing tenure: } \\
\text { Owner occupied } \\
\text { Not owned }\end{array}$ & & & 0.03 & 0.864 \\
\hline $\begin{array}{l}\text { Employment: } \\
\text { Employed } \\
\text { Not employed }\end{array}$ & & & 0.03 & 0.859 \\
\hline $\begin{array}{l}\text { Smoking status: } \\
\text { Non-smoker } \\
\text { Ex-smoker } \\
\text { Occasional smoker } \\
\text { Daily smoker }\end{array}$ & & & 2.77 & 0.041 \\
\hline Covariates & $B$ & $\beta$ & SEM & $P$ \\
\hline $\begin{array}{l}\text { Maternal age (years) } \\
\text { Socioeconomic status } \\
\text { Stress } \\
\text { Social support }\end{array}$ & $\begin{array}{l}0.162 \\
0.365 \\
0.062 \\
0.268\end{array}$ & $\begin{array}{l}0.190 \\
0.057 \\
0.028 \\
0.107\end{array}$ & $\begin{array}{l}0.051 \\
0.266 \\
0.089 \\
0.097\end{array}$ & $\begin{array}{l}0.002 \\
0.171 \\
0.485 \\
0.006\end{array}$ \\
\hline
\end{tabular}

*Adjusted ${ }^{2} 0.103$, d.f. 17 and 626, $F 5.22, P \ll 0.001$.
Although it has been suggested in the past that women might gain disproportionate amounts of weight following their first pregnancy (Sheldon, 1949), a recent analysis of long-term weight gain in primiparous and multiparous women from Southeast London (Harris et al. 1997a) found that the strong association between prepregnant BMI and long-term weight gain was independent of parity. Therefore, it is unlikely that the absence of nulliparous women from the sample would have influenced the findings of the present study.

The results of the present study therefore indicate that gravidity is not independently associated with maternal BMI in a community with a high prevalence of obesity. Previous studies have shown that women from other parts of Africa do not gain weight in association with pregnancy (Prentice et al. 1981), although these studies examined undernourished women from rural subsistence farming communities (The Gambia; Prentice et al. 1981), which differ markedly from the comparatively obese women sampled in the present study. The prevalence of overweight $\left(\mathrm{BMI} \geq 25 \mathrm{~kg} / \mathrm{m}^{2}\right.$ ) in the present community was $63.4 \%$, of whom $30.3 \%$ were obese $\left(B M I>30 \mathrm{~kg} / \mathrm{m}^{2}\right)$. These values contrast starkly with the equivalents for English women, $50.5 \%$ of whom are classified as either overweight (32.9\%) or obese (17.5\%) (Health Survey for England 1995, 1997). Because longitudinal studies clearly show high prepregnant weight to be associated with greater overall weight gains (Schauberger et al. 1992; Stevens-Simon \& McAnarney, 1992; Boardley et al. 1995), it is unlikely that the absence of an effect of gravidity on BMI in the present study can be explained by obese mothers having potentially less scope to gain weight than mothers of relatively lower body weight. However, the gestational gains of obese women are known to be lower than those of lighter women, on average (Institute of Medicine, 1990). Since gestational weight gain is undeniably one of the most important risk factors for maternal obesity (Greene et al. 1988; Keppel \& Taffel, 1993; Parker \& Abrams, 1993; Boardley et al. 1995; Scholl et al. 1995; Harris et al. 1997b,c), it is perhaps not surprising that no uniform association between gravidity and maternal BMI is seen in such an obese population.

While the results of the present study suggest that overweight women may not be at increased risk of maternal obesity, BMI was found to be independently associated with smoking behaviour, age and level of social support. It is well established that younger mothers who smoke daily have lower BMI than their older, non-smoking peers (Brown et al. 1992), although few studies have examined the effect of social support on body weight. In the present study, mothers with high levels of social support had significantly higher BMI, even after accounting for different levels of stress or socioeconomic status (see Tables 2 and 3). Social support represents a cluster of social factors, which imply that the more close friends, membership of organizations, and close family ties a person has, the more likely that person is to be healthy and happy (Bruhn \& Philips, 1984). However, the feelings of acceptance and contentment that result from the buffering effects of social support (Bruhn \& Philips, 1984) may have led mothers in this community to accept higher body weights than they might otherwise find acceptable. Nevertheless, social support is highly culturally specific 
Table 3. The final analysis of covariance model with maternal BMI as the dependent variable ${ }^{*}$

\begin{tabular}{|c|c|c|c|c|}
\hline \multirow{2}{*}{$\frac{\text { Factors }}{\text { Gravidity: }}$} & \multicolumn{2}{|c|}{$\begin{array}{l}\text { Adjusted maternal } \\
\text { BMI }\left(\mathrm{kg} / \mathrm{m}^{2}\right)\end{array}$} & $F$ & $P$ \\
\hline & & 1.53 & 0.144 \\
\hline 1 & \multirow{2}{*}{\multicolumn{2}{|c|}{$\begin{array}{l}26.99 \\
27.88\end{array}$}} & & \\
\hline 2 & & & & \\
\hline 3 & \multicolumn{2}{|c|}{27.07} & & \\
\hline 4 & \multicolumn{2}{|c|}{29.26} & & \\
\hline 5 & \multirow{2}{*}{\multicolumn{2}{|c|}{$\begin{array}{l}27.56 \\
32.20\end{array}$}} & & \\
\hline 6 & & & & \\
\hline 7 & \multicolumn{2}{|c|}{31.20} & & \\
\hline 8 & \multicolumn{2}{|c|}{29.14} & & \\
\hline 9 & \multicolumn{2}{|c|}{24.99} & & \\
\hline Smoking status: & & & 2.86 & 0.036 \\
\hline Non-smoker & \multirow{4}{*}{\multicolumn{2}{|c|}{$\begin{array}{l}29 \cdot 21 \\
27 \cdot 24 \\
32 \cdot 22 \\
25 \cdot 29\end{array}$}} & & \\
\hline Ex-smoker & & & & \\
\hline Occasional smoker & & & & \\
\hline Daily smoker & & & & \\
\hline Covariates & $B$ & $\beta$ & SEM & $P$ \\
\hline Maternal age (years) & 0.163 & 0.192 & 0.050 & 0.001 \\
\hline Socioeconomic status & 0.384 & 0.059 & 0.254 & 0.132 \\
\hline Stress & 0.063 & 0.028 & 0.089 & 0.477 \\
\hline Social support & 0.269 & 0.107 & 0.097 & 0.006 \\
\hline
\end{tabular}

"Adjusted $\digamma^{2} 0.106$, d.f. 15 and $626, F 5.93, P \ll 0.001$.

(Bruhn \& Philips, 1984; Bruhn, 1991), and therefore, it is probably inappropriate to generalize this result to other communities. In contrast to the findings of others (Rona \& Morris, 1982; Baecke et al. 1983) no independent association between socioeconomic status and BMI was observed. In part, the absence of an effect of socioeconomic status on body weight may have been the result of the relative homogeneity of the population in terms of its socioeconomic status.

Although the mothers eligible for inclusion in the present study were of lower gravidity than the mothers who were excluded, this should not have affected the external validity of the study because there was no independent effect of gravidity on maternal nutritional status (BMI) within this population (Table 3 ). Consequently, it appears that overweight women are at greater risk of weight gain generally, but there is little evidence to suggest that they are at any increased risk of maternal obesity, when compared with women of lower BMI.

\section{Acknowledgements}

The authors would like to thank the 'Birth to Ten' research assistants and study participants who made this project possible. 'Birth to Ten' is a multi-disciplinary longitudinal study which receives financial and logistic support from: the Urbanisation and Health Program of the Medical Research Council; the Anglo-American and DeBeers Chairman's Educational Trust; the Centre for Science Development of the Human Sciences Research Council; the University of the Witwatersrand; the Institute for Behavioural Sciences at the University of South Africa and numerous corporate donors. Helen Harris was supported by the Dev R Fund of the University of Greenwich, and George Ellison was supported by a Scientific Exchange grant from the Royal Society and a research grant from the Simon Population Trust. Thanks also go to Noel Cameron and Peggy Gordon-Larsen for their contributions to the manuscript.

\section{References}

Baecke JAH, Burema J, Frijters JER, Hautvast JGAJ \& Van der Wiel-Wetzels WAM (1983) Obesity in young Dutch adults: I, socio-demographic variables and body mass index. International Journal of Obesity 7, 1-12.

Boardley DJ, Sargent RG, Coker AL, Hussey JR \& Sharpe PA (1995). The relationship between diet, activity, and other factors, and postpartum weight change by race. Obstetrics and Gynecology 86, 834-838.

Brown JE, Kaye SA \& Folsom AR (1992) Parity-related weight change in women. International Journal of Obesity 16, 627-631.

Bruhn JG (1991) People need people. Perspectives on the meaning and measurement of social support. Integrative Physiological and Behavioural Science 26, 325-329.

Bruhn JG \& Phillips BU (1984) Measuring social support: a synthesis of current approaches. Journal of Behavioural Medicine 7, 151-169.

Cederlöf R \& Kaij L (1970) The effect of childbearing on bodyweight. A twin control study. Acta Psychiatrica Scandinavica 219, Suppl., 47-49.

Ellison GTH, Wagstaff L, Cameron N \& De Wet T (1997a) Geographical differences in infant feeding patterns in disadvantaged communities. South African Medical Journal 87, $1025-1026$.

Ellison GTH, Wagstaff L \& De Wet T (1997b) Sociodemographic differences in infant feeding practices amongst children from Johannesburg and Soweto enrolled in South Africa's Birth to Ten study. Proceedings of the Nutrition Society 56, 313A.

Greene GW, Smiciklas-Wright H, Scholl TO \& Karp RJ (1988) Postpartum weight change in pregnancy: how much of the weight gained in pregnancy will be lost after delivery? Obstetrics and Gynecology 71, 701-707.

Harris HE, Ellison GTH \& Holliday M (1997a) Is there an independent association between parity and maternal weight gain? Annals of Human Biology 24, 507-519.

Harris HE, Ellison GTH, Holliday M \& Lucassen A (1997b) The impact of pregnancy on the long-term weight gain of primiparous women in England. International Journal of Obesity 21, 747-755.

Harris HE, Ellison GTH, Holliday M \& Lucassen A (1997c) Do the increased weight gain recommendations for pregnancy predispose parous women to obesity? Proceedings of the Nutrition Society 56, 154A.

Harris HE, Ellison GTH, Richter LM \& De Wet T (1996) Sociodemographic correlates of body mass index among African women from Johannesburg and Soweto. Annals of Human Biology 23, 173.

Health Survey for England 1995 (1997) Series HS no. 5 (Volume I: Findings) [P Prescott-Clarke and P Primatesta, editors]. London: H.M. Stationery Office.

Heliövaara M \& Aromaa A (1981) Parity and obesity. Journal of Epidemiology and Community Health 35, 197-199.

Institute of Medicine (1990) Nutrition During Pregnancy. Washington, DC: National Academy Press.

Keppel KG \& Taffel SM (1993) Pregnancy-related weight gain and retention: implications of the 1990 Institute of Medicine guidelines. American Journal of Public Health 83, $1100-1103$.

Öhlin A \& Rössner S (1990) Maternal body weight development after pregnancy. International Journal of Obesity 14, 159-173.

Parker JD \& Abrams B (1993) Differences in postpartum weight retention between black and white mothers. Obstetrics and Gynecology 81, 768-774. 
Prentice AM, Whitehead RG, Roberts SB \& Paul AA (1981) Long-term energy balance in child-bearing Gambian women. American Journal of Clinical Nutrition 34, 2790-2799.

Richter LM, Yach D, Cameron N, Griesel RD \& de Wet T (1995) Enrolment into Birth to Ten (BTT): population and sample characteristics. Paediatric and Perinatal Epidemiology 9, 109-120.

Rona RJ \& Morris RW (1982) National Study of Health and Growth: social and family factors and overweight in English and Scottish parents. Annals of Human Biology 9, 147-156.

Schauberger CW, Rooney BL \& Brimer LM (1992) Factors that influence weight loss in the puerperium. Obstetrics and Gynecology 79, 424-429.

Scholl TO, Hediger ML, Schall JI, Ances IG \& Smith WK (1995) Gestational weight gain, pregnancy outcome, and postpartum weight retention. Obstetrics and Gynecology 86, 423-427.

Sheldon JH (1949) Maternal obesity. Lancet 2, 869-873.

Stevens-Simon C \& McAnarney ER (1992) Adolescent pregnancy. Gestational weight gain and maternal and infant outcomes. American Journal of Diseases of Children 146, $1359-1364$.

Williamson DF, Madans J, Pamuk E, Flegal KM, Kendrick JS \& Serdula MK (1994) A prospective study of childbearing and 10year weight gain in US white women 25 to 45 years of age. International Journal of Obesity 18, 561-569.

\section{Appendix}

\section{Social support}

The sum of the answer codes to the following questions: (i) If you have a really big problem and need help with money, the children, accommodation, and so on, are there people who could help you?

1: Nobody; 2: Maybe, unsure; 3: A number of people. (ii) Can you talk to your parents, other family members, or friends about any problems you may have?

1: Nobody; 2: Maybe, unsure; 3: A number of people. (iii) Can you talk to your husband or partner about any problems that you may have?

1: Never; 2: Sometimes; 3: Always. (iv) Do you feel that the father of your child or your partner makes things harder for you because of the way he acts?

1: Always; 2: Sometimes; 3: Never.

(v) Do you belong to a church group or any other organization?

1: No; 2:

Yes.

(vi) How often do you go to meetings?

1: Irregularly; 2: Once a month; 3 : Once a week.

\section{Stress}

The sum of the answer codes to the following questions: (i) During the last six months, have you or a member of your close family been in real danger of being killed?

$0:$ No; 1 : Yes.

(ii) During the last six months, has any household member died as a result of violence in the areas where you live or work?

0 : No; 1: Yes.

(iii) During the last six months, has any household member been injured as a result of violence in the areas where you live or work? (iv) During the last six months, has any household member been a victim of a violent crime (like armed robbery, assault, rape etc)?

0 : No; 1: Yes.

(v) During the last six months, did you witness a violent crime (e.g. murder, robbery, assault, rape)? 0: No; 1: Yes. (vi) During the last six months, has violence in the areas where you live or work affected your ability to obtain health care for any of your children? $\quad 0$ : No; 1: Yes. (vii) During the last six months, have you found that you are in so much debt that you don't know how you will repay the money? 0 : No; 1 : Yes. (viii) During the last six months, have you or your close family ever had too little money for basics, such as food, rent, clothes? 0 : No; 1: Yes. (ix) Have you or one of your close family not been able to find a job for more than six months? $\quad 0$ : No; 1 : Yes. (x) During the last six months, have you or anyone in your close family been seriously ill? $\quad 0$ : No; 1 : Yes. (xi) During the last six months, did any member of your close family die?

0 : No; 1: Yes.

(xii) Is there anyone in your close family with a serious disability (for example, epilepsy, mental retardation, deafness, blindness, mental illness)? 0 : No; 1: Yes. (xiii) Is there anyone in your close family that has a problem with drugs or alcohol? $\quad 0$ : No; 1: Yes. (xiv) During the lat six months, have you had a break-up with your husband or partner? 0 : No; 1 : Yes. (xv) During the last six months, has your husband or partner hit or beaten you? 0 : No; 1 : Yes. (xvi) During the last six months, have you had any serious fight or alienation from members of your family or your close neighbours? 0 : No; 1 : Yes. (xvii) During the last six months, have you or any member of your close family been arrested, had to go to court, or consulted a lawyer on a non-routine matter? 0: No; 1 : Yes. (xviii) During the last six months, have you given help (money, accommodation etc.) to close family or friends in need? 0 : No; 1 : Yes. (xix) During the last six months, have you been separated unwillingly from any of your children (excluding holidays)?

0: No; 1: Yes. (xx) During the last six months, have you experienced any problems with your child or children (such as schools closing, failure at school, problem behaviour, drugs etc.)?

0 : No; 1: Yes.

\section{Socioeconomic status}

The sum of the answer codes to the following questions:

(i) Do you have electricity in your home at the present time?

0 : No; 1: Yes.

(ii) Do you have a car at home at the present time?

0 : No; 1: Yes.

(iii) Do you have a washing machine in your home at the present time?

0 : No; 1: Yes.

(iv) Do you have medical aid or medical insurance that includes the BTT child?
0: No; 1: Yes. 